\title{
Associations between Age, Gender, Psychosocial and Health Characteristics in the Candrive II Study Cohort
}

Holly Tuokko ${ }^{\mathrm{a}}$, Anita Myers ${ }^{\mathrm{b}}$, Alexandra Jouk ${ }^{\mathrm{a}}$, Shawn Marshall ${ }^{\mathrm{c}}$, Malcolm Man-Son-Hing ${ }^{\mathrm{c}}$, Michelle M Porter ${ }^{\mathrm{d}}$, Michel Bédard ${ }^{\mathrm{e}}$, Isabelle Gélinas ${ }^{\mathrm{fg}}$, Nicol Korner-Bitensky ${ }^{\mathrm{fg}}$,

Barbara Mazer $^{\mathrm{fg}}$, Gary Naglie ${ }^{\mathrm{hij}}$, Mark Rapoport ${ }^{\mathrm{k}}$, Brenda Vrkljan ${ }^{1}$ on behalf of the Candrive II Research Team

${ }^{a}$ Centre on Aging, University of Victoria, PO Box 1700 STN CSC, Victoria BC, V8W 2Y2

${ }^{\mathrm{b}}$ School of Public Health \& Health Systems, University of Waterloo, 200 University Avenue West, Waterloo, ON, N2L 3G1

${ }^{c}$ Ottawa Hospital Research Institute, University of Ottawa, Ottawa, Ont., Canada

${ }^{\mathrm{d}}$ Faculty of Kinesiology and Recreation Management, University of Manitoba, Winnipeg, Man., Canada

${ }^{\mathrm{e}}$ Centre for Research on Safe Driving, Lakehead University, Thunder Bay, Ont., Canada

${ }^{\mathrm{f}}$ School of Physical \& Occupational Therapy, McGill University, Montreal, Que., Canada

${ }^{\mathrm{g}}$ Centre de Recherche Interdisciplinaire en Réadaptation du Montréal Métropolitain

${ }^{\mathrm{h}}$ Research Department, Toronto Rehabilitation Institute, University Health Network

${ }^{\mathrm{i}}$ Department of Medicine and Rotman Research Institute, Baycrest Geriatric Health Care Centre

${ }^{\mathrm{j}}$ Department of Medicine and Institute of Health Policy, Management and Evaluation, University of Toronto Toronto, Ont., Canada

${ }^{\mathrm{k}}$ Department of Psychiatry, University of Toronto, Toronto, Ont., Canada

${ }^{1}$ School of Rehabilitation Science, McMaster University, Hamilton, Ont., Canada

Corresponding author: Holly Tuokko, PhD, RPsych, Director, Centre on Aging, University of Victoria, PO Box 1700 STN CSC, Victoria BC, V8W 2Y2. Telephone: 011250 721-6350; Email: htuokko@uvic.ca

\section{Keywords: Older drivers; Perceptions; Attitudes; Health}




\begin{abstract}
The relations among driving-related psychosocial measures (e.g., driving comfort, attitudes toward driving) and measures of self-reported health were examined in the context of driver characteristics (i.e., age and gender) within the Canadian Driving Research Initiative for Vehicular Safety in the Elderly (Candrive II) baseline data, available for the cohort of 928 drivers, 70 years of age and older. Older members of the cohort had lower comfort scores and poorer perceptions of their driving abilities. Men reported significantly higher levels of driving comfort than women. When analyses including health were controlled for age and gender, significant relations with health status were evident for most of the psychosocial measures. These findings extend previous research and suggest that attitudes, beliefs, and perceptions about driving may be influenced by health status and act as mediators in the self-regulation process.
\end{abstract}




\section{Introduction}

The Candrive (Canadian Driving Research Initiative for Vehicular Safety in the Elderly) II study is following a large cohort of over 900 older drivers recruited from seven cities in four provinces, for up to four years (see Marshall et al. in this special issue). Those recruited into the Candrive II study were active drivers, 70 years of age and older. In addition to recording their driving practices, using an in-vehicle monitoring device, study participants underwent yearly comprehensive assessments, including a battery of psychological, health and functional measures. A major objective of the overall longitudinal Candrive II study is to develop in-office screening tools that physicians can use to determine who, among their older patients, is safe and not safe to drive.

In addition to this major objective which will be examined through predictors of crash outcomes, we are interested in understanding more about the processes underlying voluntary driving restriction and cessation. It is well known that many older drivers restrict their driving practices (e.g., drive less as they age and avoid more demanding situations such as driving at night), or stop driving of their own accord, typically without experiencing a crash (e.g., Charlton et al., 2006; Pickard et al., 2009). Psychosocial factors (e.g., perceptions, attitudes and beliefs) have been identified as central to the process of voluntary behaviour change, when studied in other contexts (e.g., smoking cessation, exercise enhancement). In previous research, measures of these constructs specific to the context of driving have been linked to self-reported restrictions in older drivers (Blanchard and Myers 2010; MacDonald et al., 2008; Myers et al., 2008; Tuokko et al., 2006), as well as objectively measured restrictions in driving exposure (i.e., distance, duration) and patterns (i.e., radius from home, driving at night and in bad weather, Blanchard and Myers, 2010; Myers et al., 2008; Myers et al., 2011). 
In this cross-sectional study, baseline data from the large Candrive II cohort were used to examine age and gender differences on several psychosocial measures developed specifically for older drivers, as well as associations with health-related measures. The purpose of this investigation was to increase our understanding about psychological processes (i.e., attitudes, beliefs, perceptions), in relation to other characteristics including age, gender, and health, underlying self-regulation by older drivers.

\section{Materials and Method}

The Candrive II study cohort was recruited through media outlets (e.g., newspapers, radio and television coverage) in seven Canadian cities (i.e., Ottawa, Toronto, Hamilton, Thunder Bay, Montreal, Winnipeg and Victoria). Only those people aged 70 years or older, with a valid driver's license, who were driving one vehicle $70 \%$ of the time when recruited, and who intended to continue driving for at least five years, were eligible to take part. Those with a medical contraindication for driving within the prior six months and those with a progressive condition that would affect their driving (e.g., Parkinson's disease) were excluded from participation. The study received ethical approval by the human research ethics board at each participating institution and each participant provided written informed consent. Participants underwent a comprehensive baseline assessment (see Marshall et al. in this special issue) that included demographic and health-related measures as well as psychosocial driving-related measures (i.e., attitudes and perceptions) and measures of driving behaviors.

The characteristics of the Candrive II cohort have been described in detail elsewhere (see Gagnon et al. in this special issue). Briefly, this sample of Canadian older drivers: was well educated (average education equivalent to a community college degree), lived in urban areas, rated their health as good or very good (72\%), performed activities of daily living well, were 
cognitively intact (Mini-Mental State Examination, Mean $=28.09, S D=1.67$ ), and drove between four and seven times per week (98\%).

For the purposes of this study, scores on three sets of psychosocial measures were examined in relation to driver characteristics (age, gender) as well as perceived health status. The first set of psychosocial measures, the 13-item Day and 16-item Night Driving Comfort Scales (DCSs) was developed inductively with older drivers (Myers et al., 2008), and is context specific (e.g., comfort in relation to traffic flow, speed, road type, behavior of other drivers). Respondents rated their comfort level on a 5-point scale from $0 \%$ (completely uncomfortable) to $100 \%$ (completely comfortable). The DCS-Day and DCS-Night scales have been shown to be hierarchic and unidimensional, with interval properties and good person $(.89 ; .96)$, item $(.98 ; .97)$, and testretest (ICC $=.70 ; .88)$ reliabilities (Myers et al., 2008). Temporal stability over one week (ICC = .89 and .92 for the DCS-Day and DCS-Night scales, respectively) has been replicated with a separate sample (Blanchard \& Myers, 2010).

The second measure, the 15-item Perceived Driving Abilities (PDA) scale, has also been shown to be hierarchic and unidimensional, with good person (.92) and item (.96) reliabilities (MacDonald et al., 2008), as well as moderate test-retest reliability (ICC=.65) over one week (Blanchard \& Myers, 2010). Respondents rated their current abilities pertaining to various aspects of driving (e.g., to see road signs at a distance, to see vehicles coming up alongside, to make an over the shoulder-check, to make quick driving decisions) on a 4-point scale as either: Poor, Fair, Good or Very Good. Total scores range from 0 to 45.

The third set of psychosocial measures was derived from the 36-item Decision Balance Plus scale (Lindstrom-Forneri et al., 2007; Tuokko et al., 2006). This measure examines positive aspects of driving relevant for the individual (pro-self; e.g., driving a vehicle is pleasurable; 9 
items), positive aspects of driving relevant for others (pro-other; e.g., others count on me being able to drive; 7 items), negative aspects of driving relevant for the individual (con-self; e.g., the financial cost of maintaining a vehicle is an increasing concern of mine; 9 items), negative aspects of driving relevant to others (con-other; e.g., my driving bothers other people; 6 items), and intention towards driving (intention; e.g., I plan to continue driving in the foreseeable future; 2 items).

In addition to the psychosocial driving-related measures, two measures pertaining to perceived health status, collected as part of the comprehensive baseline data, were selected for examination in relation to the psychosocial driving measures. The first measure was a single item from the SF-36 (Ware and Sherbourne, 1992; i.e., In general, how would you say your health is?), rated on a 5-point scale from excellent (1) to poor (5). The second measure assessed healthrelated symptoms (e.g., pain, stiffness, limited strength) in five body areas that are particularly relevant to driving (Steinfeld et al., 1999; Tuokko et al., 2007b): lower body (4 items), spine (6 items), visual system ( 2 items), central nervous system ( 5 items), and upper body (4 items). The total number of symptoms endorsed as present was summed for the body as a whole (maximum $=$ 21) and for each body area separately.

\section{Results}

The results are based on the 928 Canadian participants enrolled in the Candrive II prospective study at baseline. This sample ranged in age from 70 to $94($ Mean $=76.2, S D=4.9)$ and was comprised of 577 men (62.2\%) and 351 women (37.8\%). The men ranged in age from 70 to $94($ Mean $=76.4, S D=5.0)$ and the women ranged in age from 70 to $89($ Mean $=75.89, S D=$ 4.6), $t_{(926)}=1.9, p<.06$. The majority of the sample completed the psychosocial measures (as shown in Tables 1 and 2). 
As scores on many of the psychosocial measures were not normally distributed, nonparametric statistics (Spearman $r h o$ ) were used to examine associations with age. $T$-tests were used to examine gender differences in scores on the psychosocial measures. The results did not differ when the Mann-Whitney U test was employed for non-normally distributed measures. Hierarchical regression analyses were used to examine the relations among health status and the psychosocial measures. In each instance, age and gender were entered into the analysis first (model 1) and then the psychosocial measure were entered (model 2). Given the large number of comparisons conducted, an alpha level of $p<.01$ was considered indicative of significant effects.

Significant associations between age and scores on the psychosocial measures are shown in Table 1, while significant gender differences are shown in Table 2. The correlations in Table 1 indicate that older drivers: were less comfortable driving (day or night); had poorer perceptions of their driving abilities; perceived more concerns about their own driving; perceived others as holding negative views about their driving; and reported that they were less likely to continue driving. The pro-self (perceive own driving positively) and pro-other (perceive own driving as positive for others) perceptions of driving were not significantly associated with age, $r h o=-.015$, $p<.66, n=914 ;$ rho $=-.062, p<.060, n=914$, respectively.

Scores on the psychosocial measures that differed significantly by gender are shown in Table 2. The results indicate that men: were more comfortable driving during the day and at night; and perceived others as holding more negative views about their driving. Perceived driving ability, intent to continue driving and the pro-self, pro-other, and con-self perceptions of driving did not differ by gender $\left(t_{(911)}=.714, p<.48 ; t_{(911)}=.451, p<.65 ; t_{(912)}=.642, p<.52 ; t_{(912)}=\right.$ $1.687, p<.09 ; t_{(912)}=.92, p<.36$, respectively). 
Tables 3 and 4 show the associations of scores on the psychosocial measures with health status scores, when controlling for age and gender. Health status scores on the SF-36 item ranged from 1 (excellent) to 4 (fair) (Mean $=2.0, S D=.75, n=912)$, and the number of reported health symptoms ranged from 0 to 14 (Mean $=1.86, S D=2.49, n=913)$. When controlling for age and gender, scores on several of the psychosocial driving measures were significantly related to perceived health status (Table 3). Better health was associated with: greater driving comfort during the day and at night; better perceptions of driving abilities; and intent to continue driving. Poorer health, meanwhile, was associated with: negative views of their own driving and perceptions that others hold negative views of their driving.

When controlling for age and gender, having fewer health symptoms was related to: higher driving comfort during the day and at night and better perceptions of driving abilities. Negative views of their own driving and perceptions that others hold negative views of their driving were related to more self-reported health symptoms (Table 4).

When scores on the psychosocial driving measures were examined in relation to each of the five body areas relevant to driving, the results showed the same patterns of associations as the total number of symptoms (individual regression results not shown). Of note, visual symptoms were associated with all psychosocial measures. The number of reported health-related symptoms in each of the five areas was: 1) lower body (4 items) ranged from 0 to 3 (Mean $=.30, S D=.63, n$ =913); 2) spine (6 items) ranged from 0 to 6 (Mean $=.79, S D=1.34, n=913) ; 3)$ visual system ( 2 items) ranged from 0 to 2 (Mean $=.19, S D=.43, n=913)$; 4) central nervous system (5 items) ranged from 0 to 5 (Mean $=.32, S D=.64, n=913$ ); and 5) upper body (4 items) ranged from 0 to 3 (Mean $=.27, S D=.56, n=913$ ). As shown in Table 5, having fewer visual problems was related to all of the psychosocial measures in the expected direction: higher driving comfort 
during the day and at night; better perceptions of their driving abilities; positive perceptions of one's own driving; positive perceptions of own driving for others; and intention to continue driving. Negative views of their own driving and perceptions that others hold negative views of their driving, conversely, were significantly related with more visual problems.

\section{Discussion}

This preliminary examination of the baseline data for the Candrive II cohort showed that age and gender were related to perceptions, attitudes, and beliefs about driving. From the correlational analysis, it appeared that older drivers have more concerns about, and less comfort with, driving than the younger drivers in this sample. However, it must be noted that these correlations, although significant, are quite small possibly due to the restricted age range. Gender comparison revealed that men were more comfortable driving than women in this cohort. These findings are consistent with others studies which have noted that women tend to be less confident and hold more negative attitudes toward driving (e.g., Blanchard and Myers, 2010; Gwyther and Holland, 2012; Myers et al., 2008; Myers et al., 2011; Tuokko et al., 2007a).

Over and above the effects of age and gender, scores on the psychosocial driving measures were related to self-reported measures of health status. Most notably, driving comfort (during the day and at night), perceived driving ability, negative perceptions of one's own driving and perceptions that others hold negative views about one's driving were all significantly related to each of the measures of self-reported health status. Self-reported problems with vision were related to all of the psychosocial measures with fewer reported problems being associated with positive perceptions of one's own driving, positive perceptions of own driving for others, and intention to continue driving. Previous research has shown that vision function is significantly associated with decisions to limit driving (Brabyn et al., 2005). Brabyn et al. (2005) examined an 
extensive battery of vision tests in relation to age, gender, health and cognitive status, depression and night-driving restriction in a sample of 900 older adults. Contrast sensitivity for men and low-contrast acuity in glare for women were most predictive of night driving self-restriction as measured by self-report that they do not drive at night or responses to any of three questionnaire items assessing difficulty driving at night (i.e., I have trouble driving when there are headlights from oncoming cars in my field of view. When driving at night, objects from the side unexpectedly appear or pop up in my field of view. When driving at night in the rain, I have difficulty seeing the road because of headlights from oncoming cars.)

In other contexts, psychosocial factors (e.g., perceptions, attitudes and beliefs) have been identified as central to the process of voluntary behavior change (e.g., Bandura, 2004), while measures developed specifically for driving (e.g., driving comfort, perceived driving ability) have been linked to self-reported driving frequency and avoidance (Blanchard et al., 2010; MacDonald et al., 2008; Myers et al., 2008) as well as actual driving exposure and patterns (Blanchard and Myers, 2010; Myers et al., 2008; Myers et al., 2011). Similarly, Gwyther and Holland (2012) observed that anxious driving style and negative attitudes toward driving were independent predictors of reported avoidance of difficult driving situations.

Since it is well known that health status and driving are related, it may be that psychosocial factors act as mediators in the self-regulatory process of driving behavior change. In a survey of over 3,500 drivers aged 50+ years, Donorfio et al. (2008) found that perceived health status was positively related to driving confidence and driving enjoyment, but negatively related to voluntary driving restrictions. Our findings support these observations that health status is associated with perceptions and attitudes toward driving in our sample of drivers aged 70+ years. This work highlights the importance of bringing together psychosocial measures related to 
driving (i.e., attitudes of self and others, beliefs, comfort level, perceptions of driving abilities) and information on health status to fully understand their relation to driving behavior.

This work also extends the existing literature by including multiple psychosocial measures, unlike other studies that often use single items or measures to assess driving confidence and/or attitudes toward driving. For instance, in the study by Donorfio et al. (2008), respondents were asked questions concerning their current levels of enjoyment and confidence in driving, compared with 10 years earlier. We administered psychometrically-derived tools to assess driving comfort and perceived driving abilities that were developed inductively with older drivers (Myers et al., 2008). In addition, we administered the Decisional Balance Plus scale that contains items reflecting constructs derived from health behavior change models (Tuokko et al., 2006). Together, these instruments provided a more detailed and in-depth examination of psychosocial factors relevant to driving behavior and decision-making.

Similarly, our work extends the literature by including more comprehensive measures of health status than used in the previous research in the area. In addition to the question on perceived health status from the SF-36, which is similar to that used in Donorfio et al.'s (2008) study, we included a more detailed examination of health-related symptoms (e.g., pain, stiffness, limited strength) in five body areas that are particularly relevant to driving and have been shown to relate to driving difficulties (Tuokko et al., 2007b).

This more detailed examination of the relations among psychosocial and health factors is necessary for increasing our understanding of the psychological processes underlying selfregulation by older drivers. In the conceptual model proposed by Lindstrom-Forneri et al. (2010), psychosocial factors such as perceptions and attitudes about driving necessarily influence driving behaviors and driving behavior change. As we begin to clarify these relations, it will inform the 
development of interventions to improve older driver safety that attend to the psychosocial underpinnings of behavior change.

It must be noted that the Candrive II cohort baseline sample was comprised of largely healthy adults aged 70 years and older who were actively engaged in driving. Thus, at least some of the measures selected for this study have limited variability at baseline due to ceiling effects. Certainly, the distributions of scores on most of the measures examined were skewed, thus the findings must be viewed with caution. Moreover, this preliminary examination of the baseline data does not take into consideration other important demographic variables, does not include laboratory of clinical measures of health or vision, and is necessarily limited to only a few relevant measures.

As longitudinal data becomes available, it will be possible to extend our current understanding of factors affecting driver behavior change in this large sample of older adults. Prospective data will allow us to examine which psychosocial factors are predictive of change in driving behavior over time (self-restrictions and voluntary cessation), as well as how perceptions (e.g., comfort level and perceived driving abilities) and beliefs change with the development of new medical problems and/or driving crashes. 
Acknowledgements--- We thank the older driver participants and the Research Associates at each data collection site, without whose valuable contributions, this research would not have been possible. We acknowledge with thanks Candrive II's key partners: the National Association of Federal Retirees, Canadian Association for the Fifty-Plus (CARP), Municipal Retirees Organization Ontario, Canadian Council of Motor Transport Administrators, and Transport Canada. This paper was prepared on behalf of the Candrive II Research Team: Shawn C. Marshall, Malcolm Man-Son-Hing, Paul Boase, Michel Bédard, Anna Byszewski, Ann B. Cranney, Hillel M. Finestone, Sylvain Gagnon, Isabelle Gélinas, Michel J, Johnson, Nicol Korner-Bitensky, Linda C. Li, Barbara L. Mazer, Frank J. Molnar, Jeannette Montufar, Anita M. Myers, Gary Naglie, Jan A. Polgar, Michelle M. Porter, Mark J. Rapoport, Ian G. Stiell, Holly A. Tuokko, Brenda H. Vrkljan, George A. Wells. This work was funded by the Canadian Institutes of Health Research (grant 90429). 


\section{References}

Blanchard, R.A., Myers, A.M. 2010. Examination of driving comfort and self-regulatory practices in older adults using in-vehicle devices to assess natural driving patterns. Accident Analysis \& Prevention 42(4), 1213-1219.

Blanchard, R.A.., Myers, A.M., Porter, M.M. 2010. Correspondence between self-reported and objective measures of driving exposure and patterns in older drivers. Accident Analysis \& Prevention 42(2), 523-529.

Brabyn, J.A., Schneck, M.E., Lott, L.A., Haegerstrom-Portnoy, G. 2005. Night driving selfrestriction: vision function and gender differences. Optometry \& Vision Science 82(8), 755-764.

Charlton, J., Oxley, J., Fildes, B., Oxley, P., Newstead, S., Koppel, S., O’Hare, M. 2006. Characteristics of older drivers who adopt self-regulatory driving behaviours. Transportation Research Part F: Traffic Psychology and Behavior 9 (5), 363-373.

Donorfio, L., D’Ambrosio, L.A., Coughlin. J.F., Mohyde, M. 2008. Health, safety, self-regulation and the older driver: It's not just a matter of age. Journal of Safety Research 39, 555-561.

Gwyther, H., Holland, C. 2012. The effect of age, gender and attitudes on self-regulation in driving. Accident Analysis and Prevention 45, 19-28.

Lindstrom-Forneri, W., Tuokko, H., Garrett, D., Molnar, F. 2010. Driving as an everyday competence: A model of driving competence and behavior. Clinical Gerontologist 33, 283-297.

Lindstrom-Forneri, W., Tuokko, H., Rhodes, R. 2007. "Getting Around Town”: A preliminary investigation of the theory of planned behavior and intent to change driving behaviors among older adults. Applied Gerontology 26(4), 385-398.

MacDonald, L., Myers, A.M., Blanchard, R.A. 2008. Correspondence among older drivers' perceptions, abilities and driving behaviours. Topics in Geriatric Rehab 24, 239-252.

Marshall, S., Man-Son-Hing, M., Charlton, J., Koppel, S., Langford, J., Tuokko, H., et al. (in press). Protocol for Candrive II/Ozcandrive, a multicentre prospective older driver cohort study. Accident Analysis and Prevention.

Myers, A.M., Paradis, J., Blanchard, R.A. 2008. Conceptualizing and measuring confidence in older drivers: Development of the Day and Night Driving Comfort Scales. Arch Phys Med Rehab $89,630-640$.

Myers, A.M., Trang, A., Crizzle, A.M. 2011. Naturalistic study of winter driving practices by older men and women: Examination of weather, road conditions, trip purposes and comfort. Canadian Journal on Aging 30 (4), 577-589. 
Pickard, J.G., Tan, J., Morrow-Howell, N, Jung, Y. 2009. Older drivers retiring from the road: an application of the selective optimization with compensation model. Journal of Human Behaviour in the Social Environment 19 (2), 213-229.

Tuokko, H., McGee, P., Gabriel, G., Rhodes, R.E. 2007a. Perception, attitudes and beliefs, and openness to change: Implications for older driver education. Accident Analysis and Prevention 39, 812-817.

Tuokko, H., McGee, P., Rhodes, R.E. 2006. Decisional balance and readiness to change driving behavior in older adults: A pilot study. Physical \& Occupational Therapy in Geriatrics 24(3), 112.

Tuokko, H.A., Rhodes, R.E., Dean, R. 2007b. Health Conditions, Health Symptoms and Driving Difficulties in Older Adults. Age \& Ageing 36(4), 389-394.

Ware, J.E. Jr., Sherbourne, C.D. 1992. The MOS 36-item short-form health survey (SF-36). I. Conceptual framework and item selection. Med Care, 30(6), 473-483. 
Table 1. Correlations between scores on psychosocial measures and age.

\begin{tabular}{|c|c|}
\hline Psychosocial measure & Correlation with age \\
\hline Driving Comfort - Day $^{1}$ & $-.187, p<.001, n=915$ \\
\hline Driving Comfort - Night $^{1}$ & $-.159, p<.001, n=914$ \\
\hline Perceived Driving Abilities $^{2}$ & $-.186, p<.001, n=913$ \\
\hline Decisional Balance - Con-self ${ }^{3}$ & $-.109, p<.001, n=914$ \\
\hline Decisional Balance - Con-other ${ }^{4}$ & $-.159, p<.001, n=914$ \\
\hline Decisional Balance - Intent ${ }^{5}$ & $.121, p<.001, n=913$ \\
\hline \multicolumn{2}{|c|}{ Note: values are Spearman correlation coefficients (rho). } \\
\hline \multicolumn{2}{|l|}{${ }^{1}$ higher score $=$ greater comfort } \\
\hline \multicolumn{2}{|c|}{${ }^{2}$ higher score $=$ better perceptions of driving abilities } \\
\hline \multicolumn{2}{|c|}{${ }^{3}$ low score $=$ perceive own driving negatively } \\
\hline \multicolumn{2}{|c|}{${ }^{4}$ low score $=$ perceive others as viewing their driving negatively } \\
\hline
\end{tabular}


Table 2. Significant differences on psychosocial measures by gender.

\begin{tabular}{llllll}
\hline Psychosocial measure & Gender & $n$ & Mean $(S D)$ & $\begin{array}{c}t \text {-value } \\
(d f)\end{array}$ & $p$-value \\
\hline Driving Comfort - Day & Male & 571 & $78.42(15.32)$ & 5.48 & $<.001$ \\
& Female & 344 & $72.54(16.37)$ & $(913)$ & \\
& & & & & \\
Driving Comfort - Night & Male & 571 & $71.98(18.82)$ & 7.40 & $<.001$ \\
& Female & 343 & $61.80(22.18)$ & $(912)$ & \\
& & & & & \\
Decisional Balance - Con-other & Male & 571 & $30.86(3.35)$ & -2.70 & $<.007$ \\
& Female & 343 & $31.46(3.13)$ & $(912)$ & \\
& & & & & \\
\hline
\end{tabular}


Table 3. Significant associations with SF-36 health status, controlling for age and gender.

\begin{tabular}{|c|c|c|c|c|c|c|c|}
\hline Psychosocial measure & Model & $R$ & $R^{2}$ & $\begin{array}{l}R^{2} \\
\text { change }\end{array}$ & $\begin{array}{l}F \\
\text { change }\end{array}$ & $d f(1,2)$ & $p$-value \\
\hline \multirow[t]{2}{*}{ Driving Comfort - Day } & 1 & .13 & .02 & .02 & 7.75 & $2(910)$ & $<.001$ \\
\hline & 2 & .24 & .06 & .04 & 40.35 & 1 (909) & $<.001$ \\
\hline \multirow[t]{2}{*}{ Driving Comfort - Night } & 1 & .13 & .02 & .02 & 7.74 & $2(909)$ & $<.001$ \\
\hline & 2 & .24 & .06 & .04 & 37.41 & $1(908)$ & $<.001$ \\
\hline \multirow[t]{2}{*}{ Perceived Driving Abilities } & 1 & .13 & .02 & .02 & 7.74 & $2(908)$ & $<.001$ \\
\hline & 2 & .33 & .11 & .09 & 90.82 & $1(907)$ & $<.001$ \\
\hline \multirow[t]{2}{*}{ Decisional Balance - Intent } & 1 & .13 & .02 & .02 & 7.56 & $2(908)$ & $<.001$ \\
\hline & 2 & .23 & .05 & .03 & 32.74 & $1(907)$ & $<.001$ \\
\hline \multirow[t]{2}{*}{ Decisional Balance - Con-self } & 1 & .13 & .02 & .02 & 7.57 & $2(909)$ & $<.001$ \\
\hline & 2 & .34 & .12 & .10 & 103.48 & $1(908)$ & $<.001$ \\
\hline \multirow[t]{2}{*}{ Decisional Balance - Con-other } & 1 & .13 & .02 & .02 & 7.57 & $2(909)$ & $<.001$ \\
\hline & 2 & .27 & .07 & .05 & 57.47 & $1(908)$ & $<.001$ \\
\hline
\end{tabular}


Table 4. Significant associations with number of health symptoms, controlling for age and gender.

\begin{tabular}{|c|c|c|c|c|c|c|c|}
\hline Psychosocial measure & Model & $R$ & $R^{2}$ & $\begin{array}{l}R^{2} \\
\text { change }\end{array}$ & $\begin{array}{l}F \\
\text { change }\end{array}$ & $d f(1,2)$ & $\begin{array}{l}p- \\
\text { value }\end{array}$ \\
\hline \multirow[t]{2}{*}{ Driving Comfort - Day } & 1 & .18 & .03 & .03 & 15.19 & $2(909)$ & $<.001$ \\
\hline & 2 & .28 & .08 & .04 & 43.07 & $1(908)$ & $<.001$ \\
\hline \multirow{2}{*}{ Driving Comfort - Night } & 1 & .18 & .03 & .03 & 15.60 & $2(908)$ & $<.001$ \\
\hline & 2 & .32 & .10 & .07 & 69.13 & $1(907)$ & $<.001$ \\
\hline \multirow[t]{2}{*}{ Perceived Driving Abilities } & 1 & .18 & .03 & .03 & 15.19 & $2(907)$ & $<.001$ \\
\hline & 2 & .35 & .12 & .09 & 89.32 & $1(906)$ & $<.001$ \\
\hline \multirow[t]{2}{*}{ Decisional Balance - Con-self } & 1 & .18 & .03 & .03 & 15.27 & $2(908)$ & $<.001$ \\
\hline & 2 & .35 & .13 & .09 & 96.06 & $1(907)$ & $<.001$ \\
\hline \multirow[t]{2}{*}{ Decisional Balance - Con-other } & 1 & .18 & .03 & .03 & 15.27 & $2(908)$ & $<.001$ \\
\hline & 2 & .26 & .07 & .03 & 32.97 & $1(907)$ & $<.001$ \\
\hline
\end{tabular}


Table 5. Significant associations with number of visual symptoms, controlling for age and gender.

\begin{tabular}{|c|c|c|c|c|c|c|c|}
\hline Psychosocial measure & Model & $R$ & $R^{2}$ & $\begin{array}{l}R^{2} \\
\text { change }\end{array}$ & $\begin{array}{l}F \\
\text { change }\end{array}$ & $d f(1,2)$ & $\begin{array}{l}p- \\
\text { value }\end{array}$ \\
\hline \multirow[t]{2}{*}{ Driving Comfort Scale - Day } & 1 & .13 & .02 & .02 & 7.52 & $2(909)$ & $<.001$ \\
\hline & 2 & .26 & .07 & .05 & 52.38 & $1(908)$ & $<.001$ \\
\hline \multirow[t]{2}{*}{ Driving Comfort Scale - Night } & 1 & .13 & .02 & .02 & 7.66 & $2(908)$ & $<.001$ \\
\hline & 2 & .34 & .11 & .10 & 97.57 & $1(907)$ & $<.001$ \\
\hline \multirow[t]{2}{*}{ Perceived Driving Abilities } & 1 & .13 & .02 & .02 & 7.53 & $2(907)$ & $<.001$ \\
\hline & 2 & .33 & .11 & .09 & 90.92 & $1(906)$ & $<.001$ \\
\hline \multirow[t]{2}{*}{ Decisional Balance - Pro-self } & 1 & .13 & .02 & .02 & 7.58 & $2(908)$ & $<.001$ \\
\hline & 2 & .15 & .02 & .01 & 6.69 & $1(907)$ & $<.010$ \\
\hline \multirow[t]{2}{*}{ Decisional Balance - Pro-other } & 1 & .13 & .02 & .02 & 7.58 & $2(908)$ & $<.001$ \\
\hline & 2 & .16 & .03 & .01 & 7.60 & $1(907)$ & $<.006$ \\
\hline \multirow[t]{2}{*}{ Decisional Balance - Con-self } & 1 & .13 & .02 & .02 & 7.58 & $2(908)$ & $<.001$ \\
\hline & 2 & .33 & .11 & .09 & 89.72 & $1(907)$ & $<.001$ \\
\hline \multirow[t]{2}{*}{ Decisional Balance - Con-other } & 1 & .13 & .02 & .02 & 7.58 & $2(908)$ & $<.001$ \\
\hline & 2 & .20 & .04 & .03 & 23.53 & $1(907)$ & $<.001$ \\
\hline \multirow[t]{2}{*}{ Intention } & 1 & .13 & .02 & .02 & 7.54 & $2(907)$ & $<.001$ \\
\hline & 2 & .19 & .03 & .02 & 16.76 & $1(906)$ & $<.001$ \\
\hline
\end{tabular}

